\title{
Perancangan Sistem Informasi Penerimaan Karyawan Pada PT. Sintang Raya
}

\author{
Rabiatul Adwiya, Muhamad Nasihin \\ ${ }^{1,2}$ Universitas Bina Sarana Informatika, Pontianak \\ Email: ${ }^{[1]}$ rabiatul.rba@bsi.ac.id, ${ }^{[2]}$ muhamad.mhn@bsi.ac.id
}

\begin{abstract}
ABSTRAK - Seleksi penerimaan karyawan merupakan proses elimininasi calon karyawan untuk mendapatkan karyawan terbaik. Jumlah calon karyawan yang mendaftar pada setiap pembukaan lowongan kerja pada PT. Sintang Raya sangat banyak, sedangkan jumlah staf yang menyeleksi sangat sedikit, terutama pada proses seleksi administrasi dan proses uji kompetensi. Penulis bermaksud melakukan penelitian untuk memecahkan permasalahan yang dialami oleh PT. Sintang Raya dengan merancang Sistem Informasi Penerimaan Karyawan. Rancangan sistem informasi penerimaan karyawan ini menyediakan fasilitas bagi calon karyawan seperti pendaftaran secara online, mengikuti seleksi ujian onlinedan pengumuman kelulusan. HRD dapat menyeleksi berkas administrasi dan menentukan hasil kelulusan wawancara, Tim Penyeleksi dapat mengolah soal, kunci jawaban dan mengoreksi jawaban dari calon karyawan, serta Direktur dapat mengakses laporan penerimaan karyawan secara langsung. Rancangan sistem ini diharapkan dapat membantu meningkatkan kinerja PT. Sintang Raya untuk setiap periode penerimaan karyawan.
\end{abstract}

\section{Kata Kunci : Sistem Informasi, Seleksi, Uji Kompetensi, Penerimaan Karyawan}

ABSTRACT_Employee acceptance is a process of eliminating applicants to get the best employees. The number of applicants who register at each job opening at PT. Sintang Raya is very large, while the number of staff is a few, especially in the administrative selection process and competency test process. Authors intends to do research to solve the problems that experienced by PT. Sintang Raya by designing an Employee Acceptance Information System. The design of the employee acceptance information system provides facilities for applicants such as online registration, participating in the online exam selection and graduation announcement. Human Resource Department can select administrative files and determine the results of graduation interviews, the Selection Team can process questions, answer keys and correct answers from applicants, and the Director can access employee acceptance reports directly. This system design is expected to help improve the performance of PT. Sintang Raya for each employee acceptance period

Index Terms: Information Systems, Selection, Competency Test, Employee Acceptance 


\section{PENDAhUluan}

Perkembangan teknologi informasi dan komunikasi yang sangat pesat ini, internet telah menjadi kebutuhan primer bagi manusia. Hampir di semua aspek kehidupan tidak terlepas dari penerapan teknologi, terutama internet, begitu pula pada instansiinstansi pemerintah dan swasta, serta perusahaan dan industri. Namun di era yang serba maju ini, masih banyak juga instansi dan perusahaan yang belum menerapkan kecanggihan teknologi yang ada dalam proses administrasi perkantorannya.

PT. Sintang Raya adalah perusahaan yang bergerak di sektor agrobisnis yang memfokuskan kegiatan bisnisnya pada sektor perkebunan dan pabrik kelapa sawit. Selain mengelola proyek perkebunan inti, PT. Sintang Raya juga mengembangkan proyek-proyek perkebunan plasma yang dimiliki oleh masyarakat setempat. Program plasma ini didanai melalui skema kredit yang tersedia untuk anggota Koperasi Primer (KKPA) dan didukung oleh pemerintah, sebagai sarana untuk mengembangkan perkebunan yang dimiliki oleh anggota Koperasi. Selain itu Perseroan juga mengembangkan proyek-proyek perkebunan plasma di bawah program Petani Perkebunan Inti (PIR-Trans) untuk mendukung program transmigrasi.

Pada prakteknya, dalam proses administrasinya PT. Sintang Raya belum sepenuhnya menerapkan sistem yang terkomputerisasi, padahal di era yang serba canggih saat ini, sistem yang terkomputerisasi tentunya dapat mempermudah dan memperlancar proses administrasi di perusahaan. Salah satunya adalah pada saat proses membukan lowongan pekerjaan dan penerimaan karyawan baru.

Penermaan calon karyawan ini terkadang menjadi hal yang cukup sulit dilakukan apabila jumlah calon karyawan sangat banyak dan juga memiliki berbagai ragam latar belakang serta kriteria-kriteria penerimaan karyawan yang ditetapkan terkadang kompleks atau bertentangan dengan latar belakang calon karyawan yang mendaftar. Hal ini dikarenakan proses seleksi dilakukan secara manual tanpa
Adwiya, Rabiatul (2019)

bantuan software sehingga akan sangat merepotkan bagi Human Resource Deparment yangjumlah stafnya sedikit.

Berdasarkan uraian tersebut, maka penulis berupaya untuk memberikan solusi agar proses penerimaan karyawan baru pada PT. Sintang Raya bisa lebih efektif dan efisien dengan merancang Sistem Informasi Penerimaan Karyawan.

\section{METODOLOGI PENELITIAN}

Metode penelitian yang digunakan adalah metode deskriptif yang bertujuan untuk membuat deskripsi, gambaran atau lukisan secara sistematis, faktual dan akurat mengenai fakta-fakta pada objek yang diselidiki kemudian merancang sistem dari data-data masukan kiriteria dan persyaratan yang harus dipenuhi oleh calon karyawan yang mendaftar pada pembukaan lowongan pekerjaan di PT. Sintang Raya.

\section{Metode Pengembangan Perangkat Lunak Waterfall}

Metode pengembangan perangkat lunak yang penulis gunakan adalah Metode Waterfall. Metode ini menyediakan pendekatan alur hidup perangkat lunak secara sekuensial atau terurut dimulai dari analisis, desain, pengkodean, pengujian. Namun pada penelitian kali ini, penulis menerapkan hingga tahap Desain saja, dengan harapan nantinya dapat menjadi acuan bagi PT. Sintang Raya dalam proses rancang bangun sistem aplikasi yang sesuai dengan kebutuhan perusahaan.

1. Analisis

Pada tahapan ini, Peneliti melakukan analisa pada objek penelitian yaitu PT. Sintang Raya, mengenai spesifikasi, kriteria dan persyaratan lowongan pekerjaan yang akan dibuka yang nantinya dikategorikan sebagai Dokumen Calon Karyawan (DOK), proses seleksi DOK, proses uji kompetensi serta proses wawancara bagi calon karyawan yang telah lulus seleksi administrasi dan uji kompetensi.

2. Desain

Berdasarkan hasil observasi dan wawancara pada objek penelitian, yaitu PT. Sintang Raya, peneliti merancang Sistem Informasi Penerimaan Karyawan, 
yang mana hasilnya diharapkan dapat menjadi acuan ketika nanti PT. Sintang Raya ingin membangun sistem aplikasi berbasis web.

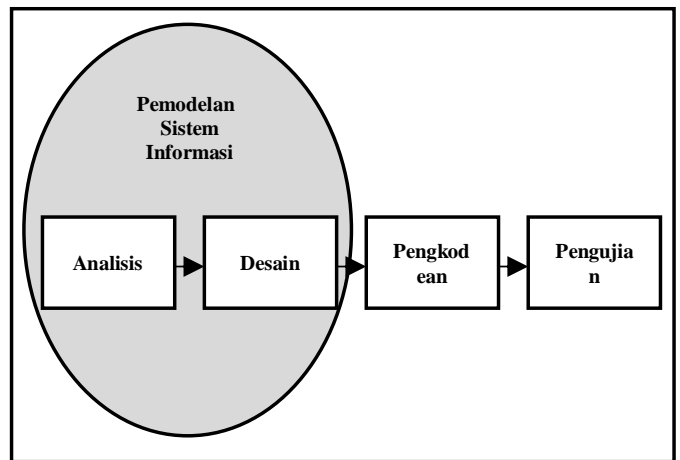

Gambar 1. Ilustrasi Metode Pengembangan Perangkat Lunak Waterfall

\section{Teknik Pengumpulan Data}

Untuk mendukung Metode Pengembangan Perangkat Lunak yang digunakan, maka penulis menerapkan beberapat Teknik Pengumpulan Data:

1. Pengamatan (Observasi)

Penulis melakukan pengamatan-pengamatan langsung terhadap kegiatan yang berhubungan dengan pembahasan penelitian. Hasil dari pengamatan tersebut langsung dicatat oleh penulis dan dari kegiatan observasi dapat diketahui kelebihan dan kekurangan dari proses yang berlangsung.

2. Studi Pustaka

Selain melakukan kegiatan diatas penulis juga melakukan studi kepustakaan melalui referensi buku-buku, jurnal dan artikel-artikel di internet.

\section{HASIL DAN PEMBAHASAN}

\section{Analisis Kebutuhan}

Rancangan Sistem Informasi Penerimaan Karyawan ini memiliki dua kebutuhan sistem, yaitu kebutuhan fungsional dan kebutuhan non fungsional, dimana kebutuhan fungsional terdiri dari beberapa fungsi utama yang berhubungan dan saling mendukung dan kebutuhan non fungsional sistem ini berfungsi mendukung kelancaran fungsi utama sehingga menghasilkan rancangan sistem yang diinginkan.

1. Analisa Kebutuhan Fungsional

Kebutuhan fungsional ini berkaitan dengan apa saja yang dapat dilakukan oleh sistem dengan fungsinya. Sistem ini dirancang dengan empat level user:

a. Level Calon Karyawan

1) Pada level calon karyawan, sistem dapat memberikan informasi lowongan pekerjaan dan status kelulusan seleksi calon karyawan.

2) Calon karyawan dapat melamar pekerjaan pada lowongan pekerjaan yang tersedia dencan cara mendaftar melalui Sistem.

3) Pada saat mendaftar, Calon Karyawan cukup mengunggah berkas-berkas lamaran pekerjaan yang dipersyaratkan.

4) Jika Calon Karyawan telah lulus seleksi administrasi, maka Uji Kompetensi akan dilaksanakan melalui Sistem ini secara online.

b. Level HRD

1) Pada level HRD, staf dapat mengelola lowongan pekerjaan, yaitu menambah lowongan pekerjaan, merubah data lowongan pekerjaan yang sudah diterbitkan dan menghapus data lowongan pekerjaan yang sudah ditutup.

2) Sistem dapat menampilkan datadata calon karyawan (pelamar), yang telah mendaftar pada lowongan pekerjaan tertentu.

3) Sistem menyediakan form penilaian hasil wawancara, sehingga akan terekap sekaligus dengan hasil ujian online yang telah dilaksanakan sebelumnya.

c. Level Tim Seleksi

1) Pada level tim seleksi, staf dapat mengelola soal-soal ujian online, yaitu menambah soal baru, merubah soal yang sudah ada, menghapus soal yang sudah tidak relevan dan menentukan kunci jawaban soalsoal tersebut.

2) Pada sistem, staf juga dapat melakukan koreksi atas jawabanjawaban yang diberikan oleh calon 
karyawan pada saat pelaksanaan ujian online dan hasilnya langsung tererap dalam basis data sistem.

d. Level Direktur

Pada level direktur, direktur dapat melihat laporan dari setiap proses seleksi calon karyawan, mulai dari laporan data calon karyawan (pelamar), laporan kelulusan seleksi administrasi, laporan kelulusan ujian online dan laporan penerimaan karyawan baru yang tentunya telah disetujui oleh direktur.

2. Kebutuhan Non Fungsional

Kebutuhan non-fungsional adalah kebutuhan yang meliputi perangkat keras dan perangkat lunak yang sangat mempengaruhi berjalannya program aplikasi. Adapun kebutuhan-kebutuhan non fungsional tersebut meliputi:

a. Perangkat Keras

Perangkat keras adalah perangkat yang nyata atau terlihat yang digunakan untuk merancang Sistem Informasi Penerimaan Karyawan ini. Adapun spesifikasi perangkat keras yang dianjurkan sebagai berikut:

- Komputer (Processor AMD E11200 [1.40 Ghz], RAM 2.00 GB, Harddisk 120 GB, Monitor 14 Inch dengan Resolusi Layar Min. $1024 \times 768$ )

- Mouse

- Keyboard

b. Perangkat Lunak

Perangkat lunak adalah perangkat yang tidak nyata yang digunakan untuk merancang Sistem Informasi Penermaan Karyawan ini. Adapun perangkat lunak yang dianjurkan adalah sebagai berikut:

- Sistem Operasi Microsoft Windows 7

- Aplikasi web server XAMPP yang terdiri dari beberapa komponen didalamnya, yaituApache, PHPMyAdmin dan MySQL

- Aplikasi web browser Google Chrome dan Mozilla Firefox

\section{Rancangan Sistem}

Adwiya, Rabiatul (2019)

Rancangan sistem ini digunakan untuk mengetahui alur dari sebuah sistem aplikasi yang akan dirancang untuk penerimaan karyawan pada PT. Sintang Raya.Pada penelitian kali ini, penulis merancang sistem menggunakan Diagram Alir Data. Adapun rancangannya adalah sebagai berikut.

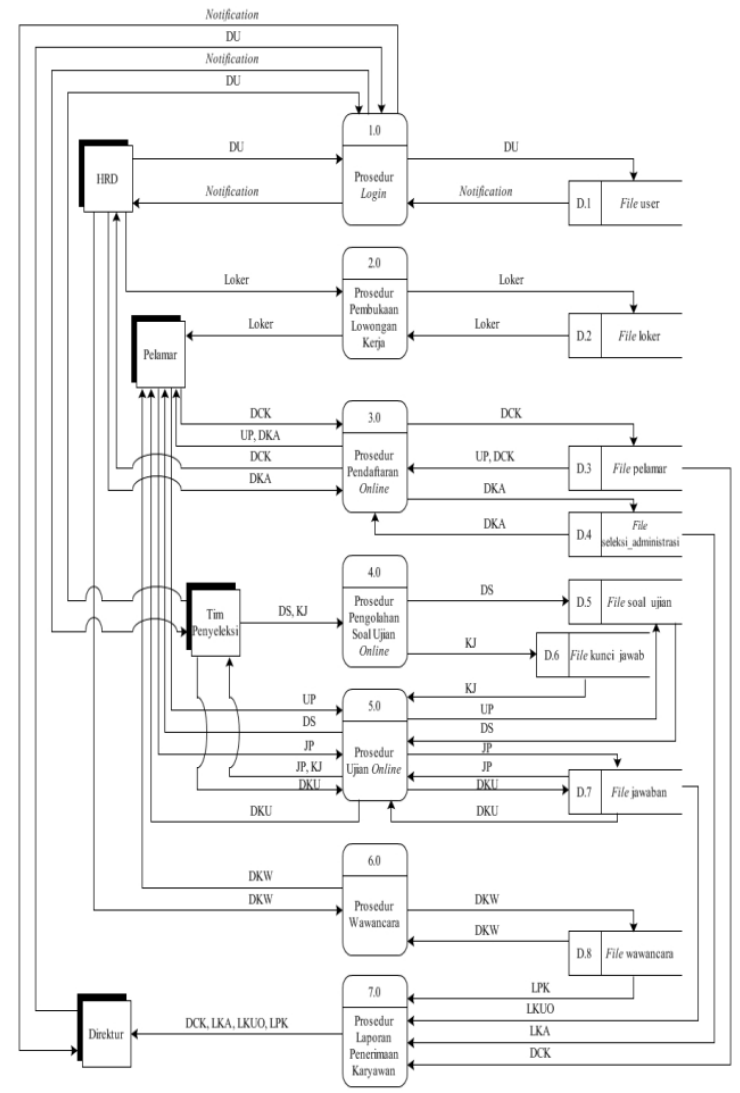

Gambar 2. Diagram Nol Rancangan Sistem Informasi Penerimaan Karyawan

Ket.

$$
\begin{array}{ll}
\text { DU } & =\text { Data User } \\
\text { Loker } & =\text { Lowongan Kerja } \\
\text { DCK } & =\text { Data Calon Karyawan } \\
\text { UP } & =\text { Username dan Password } \\
\text { DKA } & =\text { Data Kelulusan Administrasi } \\
\text { DS } & =\text { Data Soal } \\
\text { KJ } & =\text { Kunci Jawaban } \\
\text { JP } & =\text { Jawaban Pelamar } \\
\text { DKU } & =\text { Data Kelulusan Ujian } \\
\text { DKW } & =\text { Data Kelulusan Wawancara } \\
\text { LCK } & =\text { Laporan Calon Karyawan } \\
\text { LKA } & =\text { Laporan Kelulusan Administrasi } \\
\text { LKUO } & =\text { Laporan Kelulusan Ujian Online } \\
\text { LPK } & =\text { Laporan Penerimaan Karyawan }
\end{array}
$$

\section{Perancangan Basis Data}

Rancangan basis data ini digunakan untuk memberikan gambaran yang jelas basis data yang akan dirancang untuk sistem 
informasi peneriman karyawan ini. Pada penelitian kali ini, penulis merancang basis data menggunakan logical record structure. Adapun rancangannya adalah sebagai berikut.

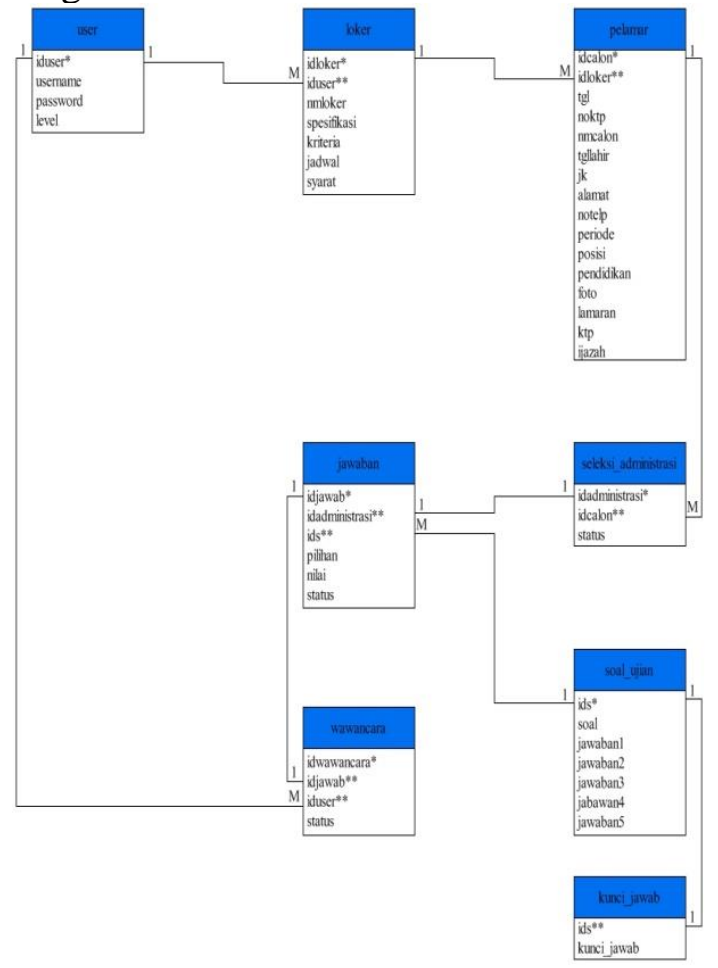

Gambar 3. Rancangan Basis Data Sistem Informasi Penerimaan Karyawan (LRS)

\section{Spesifikasi Program}

Spesifikasi program adalah penjelasan menu yang dirancang untuk sistem informasi penerimaan karyawan di PT. Sintang Raya dan fungsinya. Spesifikasi program akan dijelaskan berdasarkan masing-masing level akses pengguna.

1. Spesifikasi Program Level Pelamar

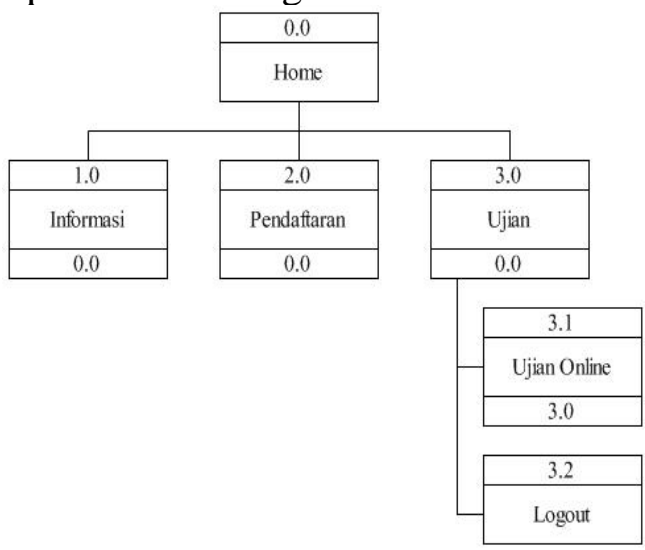

Gambar 4. HIPO Level Pelamar
2. Spesifikasi Program Level HRD

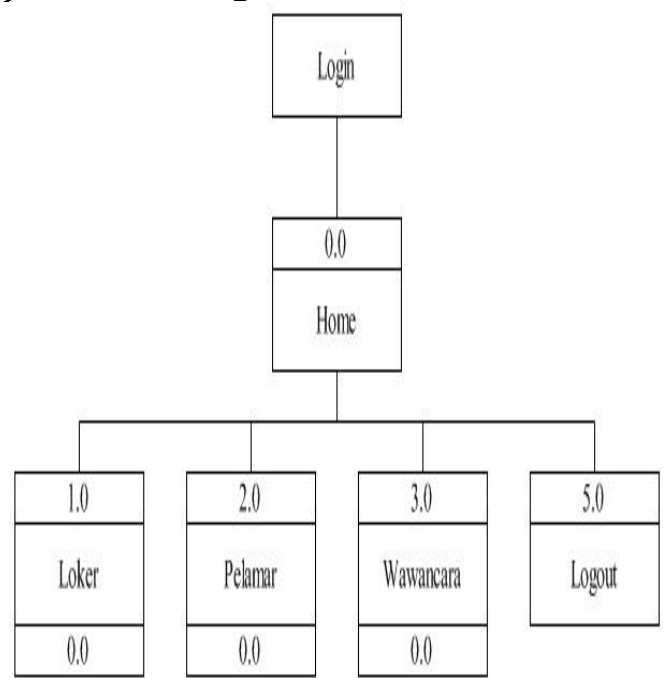

Gambar 5. HIPO Level HRD

3. Spesifikasi Program Level Tim Seleksi

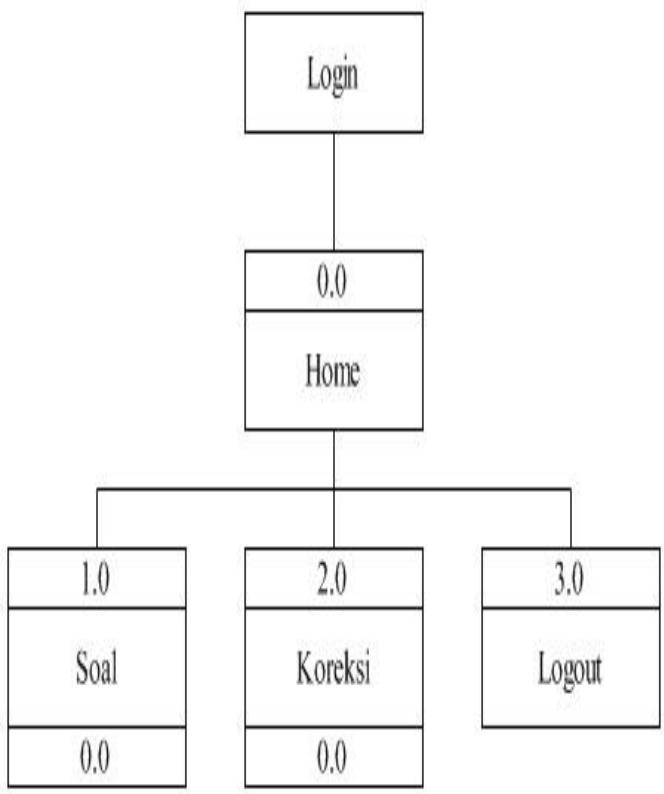

Gambar 6. HIPO Level Tim Seleksi 
4. Spesifikasi Program Level Direktur

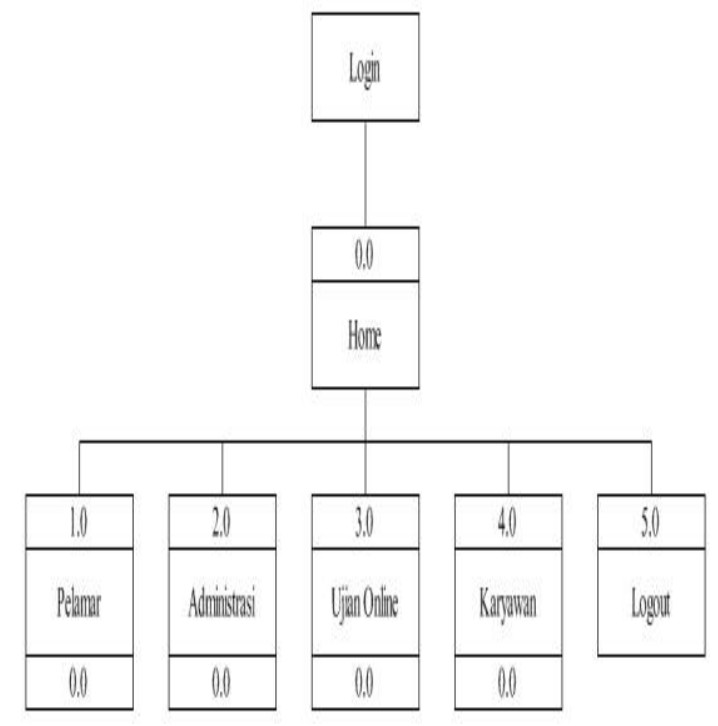

Gambar 7. HIPO Level Direktur

\section{KESIMPULAN}

Dari hasil penelitian dan perancangan sistem informasi penerimaan karyawan pada PT. Sintang Raya, dapat disimpulkan sebagai berikut:

1. Dalam proses penerimaan karyawan pada PT. Sintang Raya yang diterapkan saat ini, yang dilaksanakan oleh staf seleksi penerimaan karyawan, terkadang tanpa sengaja terjadi beberapa kesalahan dalam proses seleksi, seperti salah dalam menentukan hasil kelulusan seleksi administrasi dan hasil kelulusan uji kompetensi yang disebabkan waktu yang singkat, jumlah calon karyawan (pelamar)yang banyak dari berbagai latar belakang pendidikan dan sedikitnya jumlah staf seleksi penerimaan karyawan.

2. Rancangan sistem ini memiliki fungsifungsi yang sesuai dengan level akses yang terdiri dari Pelamar, HRD, Tim Seleksi dan Direktur.

3. Pelamar dapat mengakses informasi lowongan pekerjaan, melakukan pendaftaran, mengikuti ujian online dan memantau pengumuman kelulusan.

4. Pada rancangan sistem ini, HRD dapat menyeleksi berkas administrasi dengan mudah melalui sistem, tanpa harus memeriksa amplop berkas yang dikirimkan oleh pelamar yang dilakukan secara manual.
5. Tim Seleksi dapat mengelola soal, kunci jawaban dan mengoreksi jawaban dari Pelamar.

6. Direktur dapat mengakses laporan penerimaan karyawan secara langsung.

Selain itu terdapat beberapa saran yang dapat peneliti berikan untuk pengembangan sistem informasi ini sebagai berikut:

1. Rancangan sistem ini hanya sebagai acuan dasar untuk memberikan gambaran kepada PT. Sintang Raya, sekiranya nanti akan membangun sistem informasi penerimaan karyawan berbasis web.

2. Rancangan sistem ini dapat dikombinasikan dengan SMSGatewaysebagai notifikasi untuk penyampaian informasi kelulusan calon karyawan, baik di tahap seleksi administrasi,

ujian online maupun kelulusan akhir yaitu diterima menjadi karyawan.

\section{REFERENSI}

[1] Armiati, Sari dan Milwandhari, Shiyami. 2016. Basis Data Oracle Fundamental. Yogyakarta: Deeppublish.

[2] Berata, I.K.O. 2012. Panduan Praktis HRD \& GA. Jakarta: Niaga Swadaya.

[3] Fachruddin, Andi. 2016. Manajemen Pertelevisian Modern. Yogyakarta: CV. Andi Offset.

[4] Hasugian, Humisar dan Shidiq, A.N. 2012. Rancang Bangun Sistem Informasi Industri Kreatif Bidang Penyewaan Sarana Olahraga. ISBN:979-26-0255-0. Semarang: Semantik.

[5] Hutahaean, Jeperson. 2015. Konsep Sistem Informasi. Yogyakarta: Deeppublish.

[6] Koniyo, Andry dan Kusrini. 2007. Tuntunan Praktis Membangun Sistem Informasi Akuntansi Dengan Visual Basic dan Microsoft SQL Server. Yogyakarta: CV. Andi Offset.

[7] Ladjamudin, Al-Bahra Bin. 2013. Analisis dan Desain Sistem Informasi Yogyakarta: Graha Ilmu.

[8] Lubis, Adyanata. 2016. Basis Data Dasar. Yogyakarta: Deeppublish. 
[9] Mahatmyo, Atyanto. Sistem Informasi Akutansi Suatu Pengantar. Yogyakarta: Deeppublish.

[10] Muharto dan Ambarita, Arisandy. 2016. Metode Penelitian Sistem Informasi: Mengatasi Kesulitan Mahasiswa dalam Menyusun Proposal Penelitian. Yogyakarta: Deeppublish.

[11] Mulyani, Sri. 2016. Sistem Informasi Manajemen Rumah Sakit: Analisis dan Perancangan. Bandung: Abdi Sistematika.

[12] Puspitawati, Lilis dan Anggadini Sri Dewi. 2011. Sistem Informasi Akuntansi. Yogyakarta: Graha Ilmu.

[13] Rosa A.S, dan Shalahuddin, M. 2015. Kolaborasi Rekayasa Perangkat Lunak Terstruktur dan Berorientasi Objek. Bandung: Informatika.

[14] Shatu, Yayah Pudin. 2016. Kuasai Detail Akuntansi Laba \& Rugi. Jakarta: Pustaka Ilmu Semesta.

[15] Wahana Komputer. 2010. Shortcourse SQL Server 2008 Express. Yogyakarta: CV. Andi Offset.

[16]Zaki, Ali dan SmithDev Community. 2008. 36 Menit Belajar Komputer PHP dan MySQL. Jakarta: PT. Elex Media Komputindo 